\title{
Influence of Hot Rolling Condition on the Final Microstructure of Non- oriented Electrical Steel Fe-3.2 wt.\% Si
}

\author{
Anett Stöcker ${ }^{1, a^{*}}$, Armin Franke $^{2, b}$, Harti Hermann ${ }^{1, c}$ and Rudolf Kawalla ${ }^{1, d}$ \\ ${ }^{1}$ Institute of Metal Forming, TU Bergakademie Freiberg, Bernhard-v.-Cotta-Str. 4, 09599 Freiberg, \\ Germany \\ ${ }^{2}$ Stahlzentrum e.V., Leipziger Straße 34, 09599 Freiberg, Germany \\ a anett.stoecker@imf.tu-freiberg.de, barmin.franke@iest.tu-freiberg.de, \\ charti.hermann@imf.tu-freiberg.de, drudolf.kawalla@imf.tu-freiberg.de
}

Keywords: non-oriented electrical steel, texture, grain structure, hot rolling, annealing

\begin{abstract}
In this paper the microstructure evolution of an iron-silicon alloy with $3.2 \mathrm{wt} . \%$ silicon, throughout the manufacturing stages hot rolling, cold rolling and annealing is presented. Starting with a $35 \mathrm{~mm}$ thick feedstock, which was hot rolled to $1 \mathrm{~mm}$, with different cooling conditions, the material was cold rolled to a final thickness of $0.3 \mathrm{~mm}$ and final annealed under same conditions to show the influence of hot rolling on texture and microstructure of the final annealed material.
\end{abstract}

\section{Introduction}

Non-oriented electrical steels with a silicon content between $1 \mathrm{wt} . \%$ to $3.5 \mathrm{wt} \% \%$ are widely used as a key magnetic flux carrying material in electrical drives. Due to a strong energy saving trend, an optimization of electrical drives can be achieved by reducing hysteresis losses of non-oriented electrical steels. It is known that the magnetic properties, especially coercivity and hysteresis losses are controlled by texture, microstructure and grain size of the final annealed material. These properties depend strongly on the manufacturing process, comprising of hot rolling, cold rolling and final annealing. Alloying elements like tin, antimony and boron reduce grain size because of precipitates or segregations inside grains and on grain boundaries, which would result in inhibition of recrystallization during annealing [1].

The hot rolling conditions have a dominant influence on final properties of non-oriented electrical steel with high silicon contents of more than $2.0 \mathrm{wt} . \%$ silicon, since these alloys are only ferritic and no allotropic transformation between austenite and ferrite occurs [2]. Therefore hot rolling takes place in the ferritic phase and as a result a rather heterogeneous microstructure in the cross section characterizes the hot rolling state. The material shows elongated flat grains in center layer with a low fraction of recrystallized grains and a larger amount of equiaxed recrystallized grains exist at surface layers. Besides morphology, texture exhibits a strong through-thickness texture gradient. $[3,4,5]$

This described heterogeneous structure will remain in a certain amount in the following process steps and can lead to problems in a inline process control. Hence a homogeneous structure is the aim of hot rolling. In this paper a hot rolling procedure was conducted which lead to a more homogenous hot rolling microstructure and the impact on cold rolling and final annealing is reported.

\section{Experimental Procedure}

The chemical composition of the used steel is Si 3.2 wt.\%, Al 1.5 wt.\%, C 0.002 wt.\%, Mn 0.09 wt. $\%$ and balance Fe.

For comparison of the influence of different cooling conditions after last pass of hot rolling all other experimental settings were kept identical. The ingot reheating was carried out at $1200{ }^{\circ} \mathrm{C}$ with a duration of $30 \mathrm{~min}$ for homogenization. For hot rolling a continuous laboratory rolling mill at the 
Institute of Metal Forming of TU Bergakademie Freiberg (IMF) was used. Within 8 passes the $35 \mathrm{~mm}$ feedstock was hot rolled to $1 \mathrm{~mm}$. Hot rolling start temperature was $1150{ }^{\circ} \mathrm{C}$ and finishing temperature was $790{ }^{\circ} \mathrm{C}$. Cooling to room temperature after last pass of hot rolling was realized either by water (WC), this represents quenching, air-cooling (AC) or with a defined cooling rate of $50 \mathrm{~K} / \mathrm{h}$ in a furnace (FC). Afterwards the materials were cold rolled at a two-high cold rolling stand at the IMF within 5 passes to reach a final thickness of $0.3 \mathrm{~mm}$. An annealing process followed. The cold rolled sheets were heated to $600{ }^{\circ} \mathrm{C}$ for two minutes to look at the first recrystallized grains and observe their texture and a second annealing trial was done at $900{ }^{\circ} \mathrm{C}$ for two minutes to analyze the fully recrystallized texture and morphology.

At all stages of manufacturing microstructure was examined by light microscopy (Fig. 2). After mounting the samples, a standard metallographic procedure was applied and the specimens were etched with $3 \%$ Nital. The samples for microstructure analysis as well as for texture analysis were observed in the plane perpendicular to transversal direction (TD), see Fig. 1 a). It is known that there are differences across the total cross section. So a separation in near surface area and center area of the cross section was made, see Fig. $1 \mathrm{~b}$ ). The grain size was measured by optical microscopy by means of the linear intercept method. For a better understanding of grain shape, measurements were carried out parallel to the rolling direction (RD) which is presented by c values and parallel to the normal direction (ND) which is presented by $b$ values. A classification of the grain shape can be made by the ratio $\mathrm{c} / \mathrm{b}$. If $\mathrm{c} / \mathrm{b}$ is approximately 1 an equiaxed shape appears, if $\mathrm{c} / \mathrm{b}>1$ an elongated pancake structure appears and if $\mathrm{c}$ is infinity bands are present [3].

Texture measurements were carried out by EBSD for the total sample thickness, as well as for every region as shown in Fig. 1 b). The orientation distribution function (ODF) was calculated with the Matlab toolbox MTEX [6]. The results are presented as constant $\varphi_{2}=45^{\circ}$ section of Euler space in Bunge notation. In this section magnetic preferable orientations of cube-fiber and Goss $\{110\}<001>$ and the typical cold rolling textures and magnetic unfavorable orientations of $\alpha$-fiber and $\gamma$-fiber are found, see Fig. $1 \mathrm{c}$ ).

a)

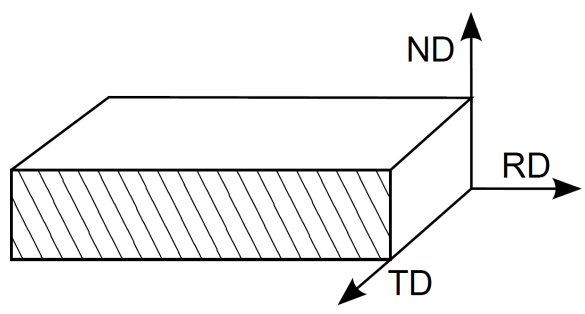

b)

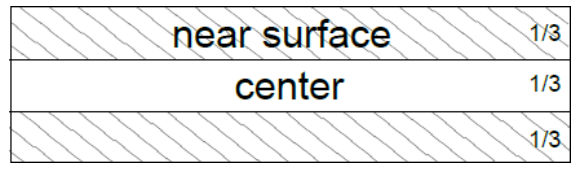

c)

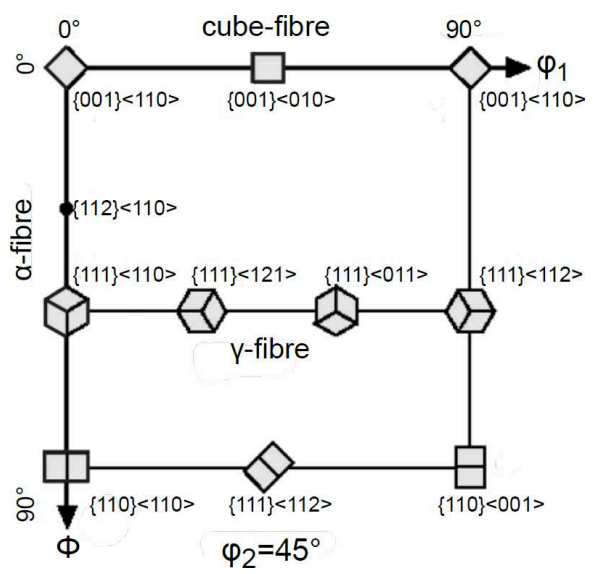

Fig. 1: a) Planes for texture and light microscopy analysis b) partition of cross section c) texture components in bcc metals displayed in $\varphi_{2}=45^{\circ}$ section of Euler space in Bunge notation [7]

\section{Results and Discussion}

Microstructure. In comparison to the investigations of Calvillo et al. [3], where a pancake structure with bands in the middle section and small-recrystallized grains near the surface of hot rolled sheets occurred, a less heterogeneous microstructure without any bands in the middle section of the sheets could be achieved by an appropriate hot rolling schedule, see Fig. 2. For samples WC and AC elongated grains are present, whereat grains in center area are more elongated than in near surface section, see $\mathrm{c} / \mathrm{b}$ values in Tab. 1. Sample AC shows a smaller average chord length than sample 
WC. This comes from a higher amount of recrystallized grains in the near surface area, which can be derived from the $\mathrm{c} / \mathrm{b}$ value of 1.62 in comparison to 2.84 in the center of the sample. In sample FC equiaxed grains predominate without any difference between near surface section and center section. Considering grain size, it would be expected that samples with the smallest grain size show the highest cold rolling force. In this case the water cooled sample shows the highest cold rolling force in first pass of cold rolling, see Fig. 3, because sample AC has a more softened state due to recovery and recrystallization. For all samples increases the cold rolling force in the following four passes.

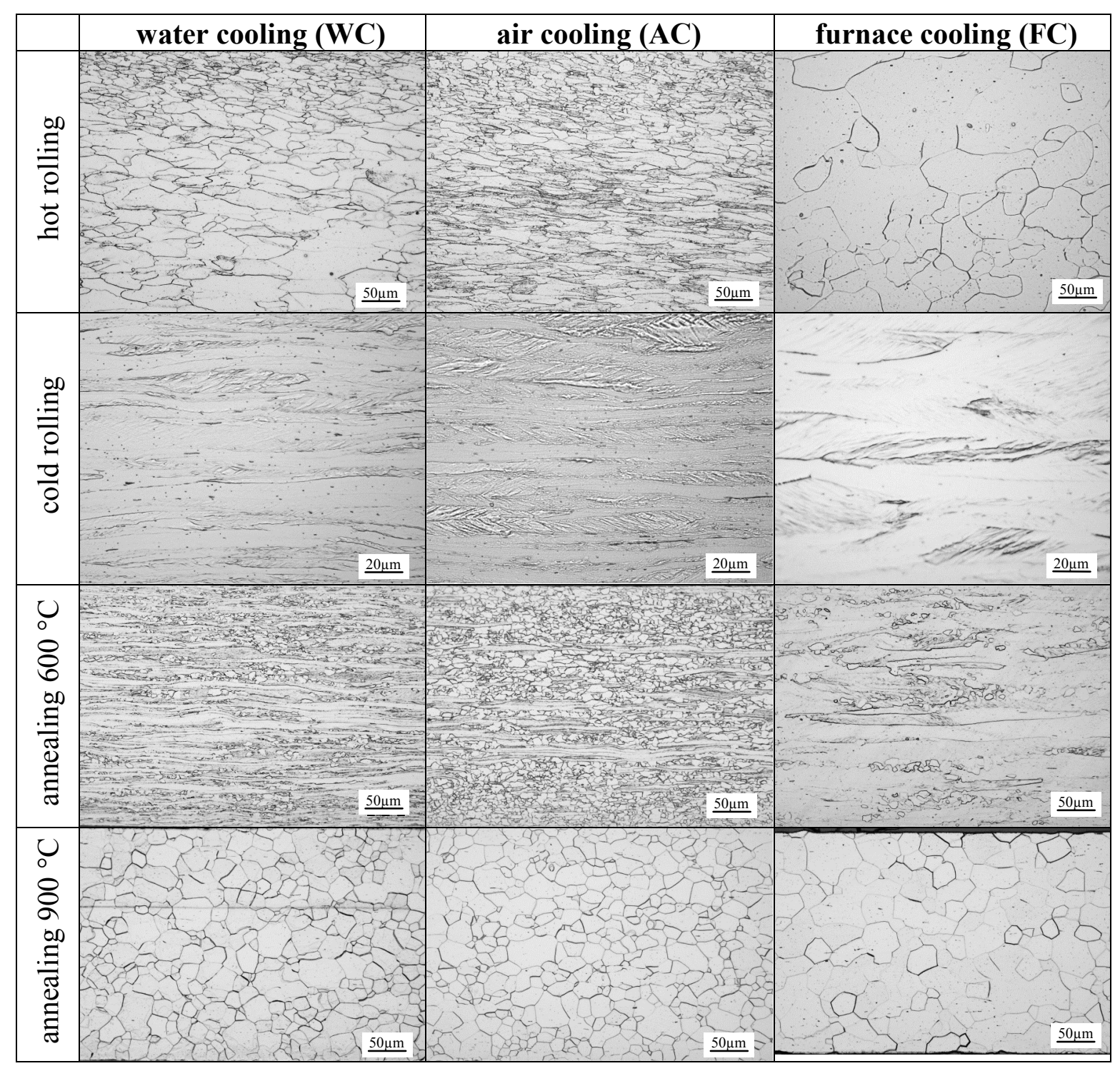

Fig. 2: Light microscope images of hot rolled, cold rolled and annealed samples, sections parallel to rolling direction

After cold rolling the materials show a deformed morphology, where sample WC has deformation bands with a few shear bands, sample AC has also deformation bands but still single deformed grains with in-grain shear bands and sample FC shows deformed grains with in-grain shear bands with double size than in sample AC, see Fig. 2. Consequently, for recrystallization during annealing different nucleation sites are present. At the light microscope images of the at $600{ }^{\circ} \mathrm{C}$ annealed samples it appears that sample AC has the highest percentage of recrystallized grains over the total sample thickness. In comparison sample WC shows only a few recrystallized grains at the grain boundaries between deformation bands. 


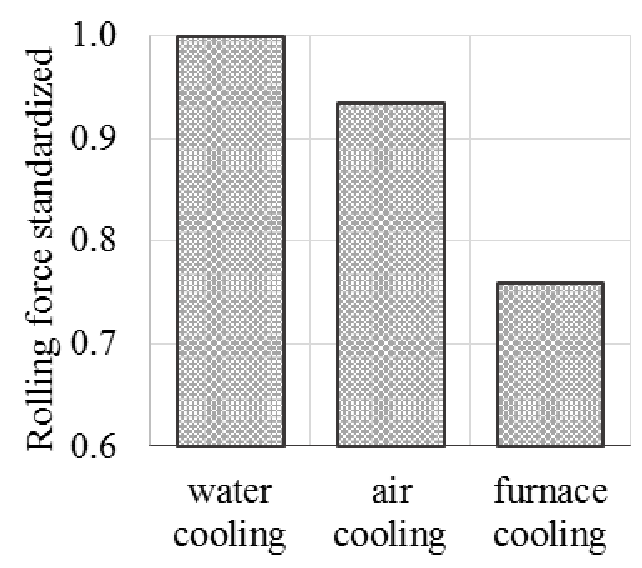

Fig. 3: Standardized cold rolling force

After final annealing at $900{ }^{\circ} \mathrm{C}$ all samples show an equiaxed grain shape with no differences between near surface areas and center section. The ration $\mathrm{c} / \mathrm{b}$ is, like the values of the hot rolled and furnace cooled samples, between 1.04 and 1.19. Recrystallization and grain growth occurred already during furnace cooling and annealing at $900^{\circ} \mathrm{C}$ (see also Figure 2). The average chord length after final annealing at $900{ }^{\circ} \mathrm{C}$ of $\mathrm{WC}$ and $\mathrm{AC}$ is similar and $\mathrm{FC}$ has a 1.5 times higher value. For applications as non-oriented electrical steels these grain sizes are too small, therefore an annealing at higher temperatures and longer times is recommended. Nevertheless, already with this difference in grain size sample FC has $20 \%$ lower core losses than sample WC.

Tab. 1: Average chord length in $\mu \mathrm{m}$ for hot rolled material and after final annealing at $900{ }^{\circ} \mathrm{C}, \mathrm{c}-$ parallel to rolling direction, $\mathrm{b}$ - parallel to normal direction

\begin{tabular}{|c|c|c|c|c|c|c|c|c|c|}
\hline \multirow[b]{2}{*}{ measuring direction } & \multicolumn{3}{|c|}{ water cooling } & \multicolumn{3}{|c|}{ air cooling } & \multicolumn{3}{|c|}{ furnace cooling } \\
\hline & $c$ & $b$ & $c / b$ & $c$ & $b$ & $c / b$ & $c$ & $b$ & $c / b$ \\
\hline \multirow{5}{*}{$\begin{array}{r}\text { total cross section } \\
\text { near surface } \\
\text { center }\end{array}$} & \multicolumn{9}{|c|}{ hot rolled samples } \\
\hline & 29.2 & 11.4 & 2.56 & 12.9 & 6.0 & 2.17 & 35.3 & 29.9 & 1.18 \\
\hline & 18.7 & 8.8 & 2.13 & 9.0 & 5.5 & 1.62 & 30.2 & 25.6 & 1.18 \\
\hline & 35.6 & 12.9 & 2.75 & 19.0 & 6.7 & 2.84 & 47.1 & 40.6 & 1.16 \\
\hline & & & fina & & (9) & (C) & npl & & \\
\hline \multirow{3}{*}{$\begin{array}{r}\text { total cross section } \\
\text { near surface } \\
\text { center }\end{array}$} & 18.4 & 16.4 & 1.12 & 16.5 & 14.6 & 1.13 & 24.6 & 21.7 & 1.13 \\
\hline & 18.0 & 17.3 & 1.04 & 16.5 & 15.2 & 1.08 & 24.5 & 21.4 & 1.15 \\
\hline & 18.7 & 15.8 & 1.19 & 16.5 & 14.0 & 1.18 & 24.7 & 22.0 & 1.12 \\
\hline
\end{tabular}

Texture. Fig. 4 presents texture of the hot rolled samples. A separation in near surface layer and center layer was made. The difference of texture in these layers is distinct. In the near surface layer a strong shear texture appears characterized by strong $\{4411\}<11118>$ and $(110)<112>$ components for sample WC and AC, whereas in sample FC a strong goss texture $(\{110\}<001>)$ appears. The center layer of sample WC and $\mathrm{AC}$ has $\{001\}<110>$ texture and $\gamma$-fiber, whereas sample FC has a pronounced $\{112\}<110>$ texture. After cold rolling and annealing at $600{ }^{\circ} \mathrm{C}$ first recrystallized grains are present. The surrounding grains are still deformed with cold rolling texture. The recrystallized grains have $<111>|| N D$ orientations ( $\gamma$-fiber). So the $\gamma$-fiber in sample WC and AC comes from recrystallized grains in comparison to sample FC where the $\gamma$-fiber is cold rolling texture (Fig. 5). 


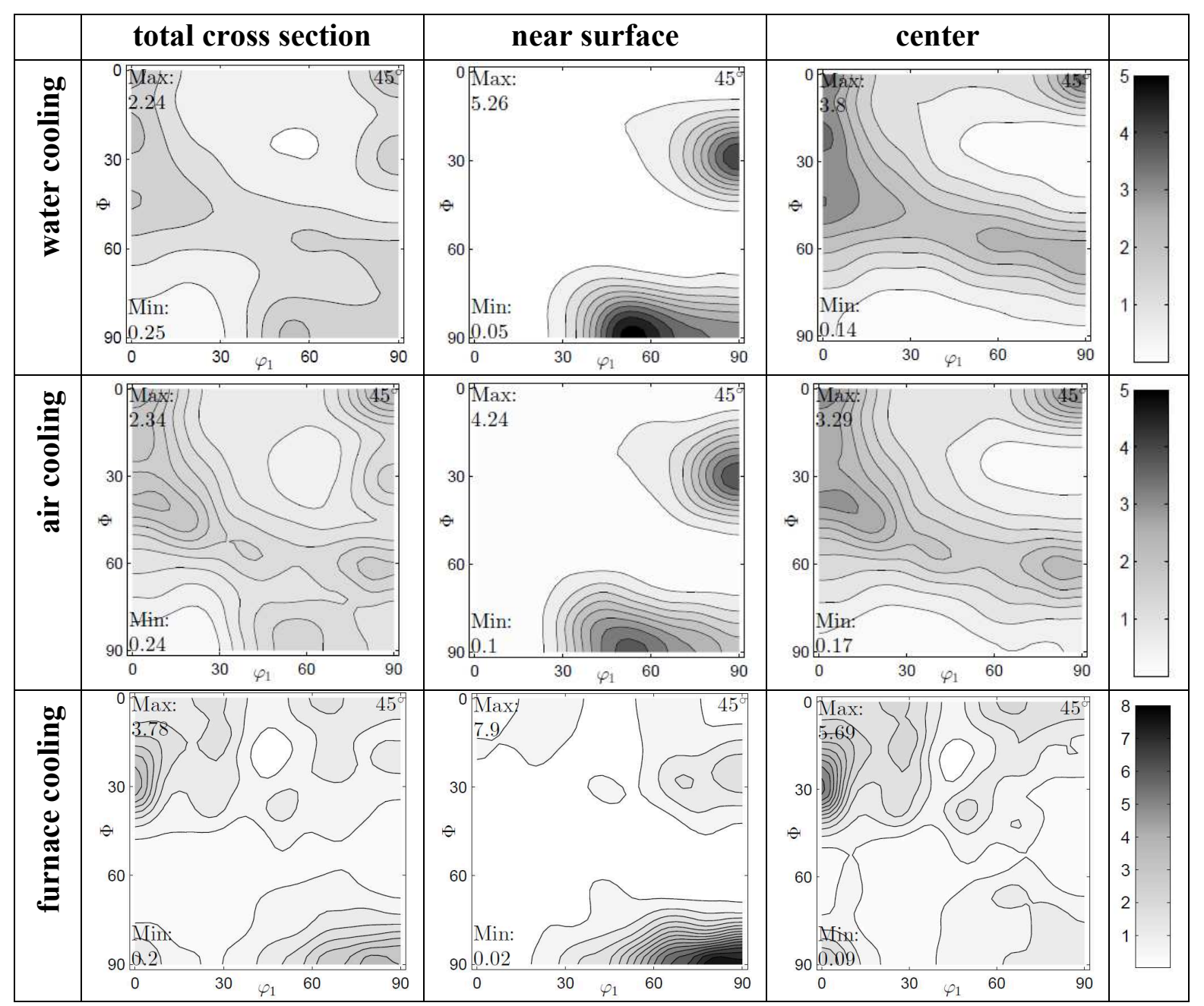

Fig. 4: ODF of hot rolled sheets, $\varphi_{2}=45^{\circ}$ section of Euler space in Bunge notation

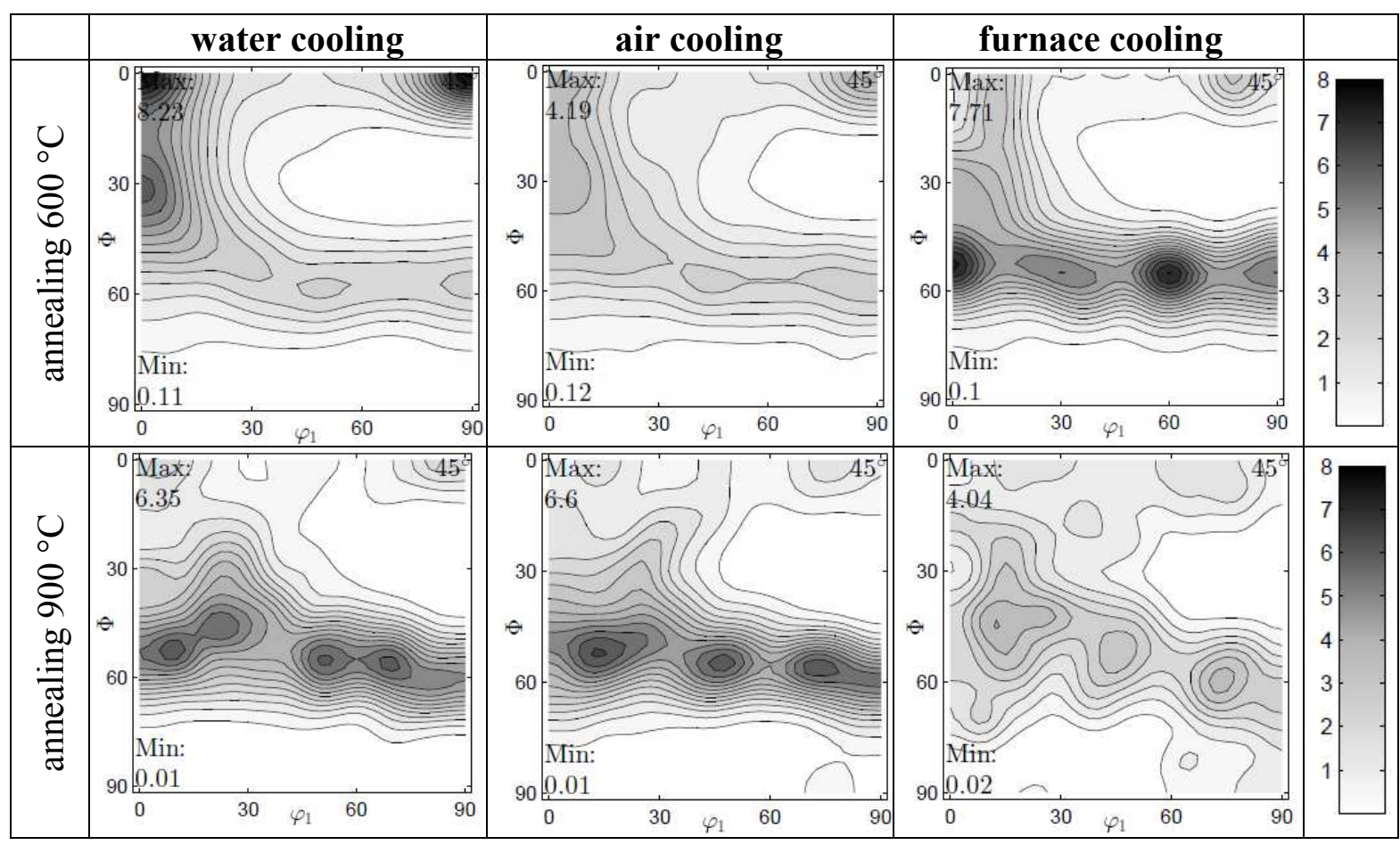

Fig. 5: ODF after annealing at $600{ }^{\circ} \mathrm{C}$ and $900{ }^{\circ} \mathrm{C}$ for $120 \mathrm{~s}$, total cross section, $\varphi_{2}=45^{\circ}$ section of Euler space in Bunge notation 
Annealing at $900{ }^{\circ} \mathrm{C}$ stimulates recrystallization of $<111>\| \mathrm{ND}$ grains so this texture dominates in sample WC and AC (Fig 5). Sample FC experience a slight randomization of $<111>|| N D$ components due to grain growth. These results are in good accordance with [8].

\section{Summary}

Homogeneous microstructure and homogeneous texture of hot rolled strip are in general for steels a precondition to achieve homogeneous properties after follow-up processes like cold rolling and annealing. For the named FeSi steel a nearly homogeneous microstructure could be set by the selection of hot rolling conditions and particularly cooling which was characterized by nearly globular grains. The morphology was analyzed by measurements of the average chord length parallel to rolling direction and parallel to normal direction to show differences and grain shape. Elongated grains were present for water and air cooling after last pass of hot rolling. An equiaxed grain shape was the result of furnace cooling after last pass of hot rolling. This cooling can be compared to a normalizing process.

The through texture gradient of the hot rolled strips is not negligible. A typical texture for ferritic hot rolling was generated with a strong shear deformation texture in the near surface layers. After cold rolling and annealing nearly globular grains and a uniform texture could be obtained for this material but texture was unfavorable to achieve the desired magnetic properties. The result could be a starting point for further investigations to produce after cold rolling and annealing a homogeneous, magnetically favored texture of hot rolled strips, also characterized by a homogeneous microstructure.

\section{Acknowledgement}

The author would like to thank the DFG for financial support within contract KA 1591/23-1.

\section{References}

[1] S.K. Chang, W. Huang, Effect of Normalizing of Hot Band on Magnetic Properties and Texture in High Silicon Non-Oriented Electrical Steels, Steel Research International 78, (2007), 340-347.

[2] O. Kubaschewski, Iron - Binary Phase Diagramms, Springer, 1982, Chapter Fe-Si, p. 136.

[3] P. R. Calvillo, N. Salazar, J. Schneider, Y. Houbaert, Microstructure characterization by EBSD of hot rolled high-silicon steel, Defect and Diffusion Forum 273-276, (2008), 69-74.

[4] D. Raabe, Overview on Basic Types of Hot Rolling Textures of Steels, Steel Research 74, (2003), 327-337.

[5] A. Stöcker, J. Schneider, T. Scholze, A. Franke, H. Hermann, R. Kawalla, Influence of cubic texture intensity of hot rolled ferritic non-oriented electrical steels on the microstructure and texture in the final processed material, IOP Conference Series: Materials Science and Engineering 82 (2015) 012070.

[6] F. Bachmann, R. Hielscher, H. Schaeben, Texture Analysis with MTEX - Free and Open Source Software Toolbox, Solid State Phenomena, 160 (2010), 63-68.

[7] H.-R. Wenk, P. Van Houtte, Texture and anisotropy, Rep. Prog. Phys. 67 (2004) 1367-1428.

[8] D. Raabe, K. Lücke, Annealing textures of BCC metals, Scripta Metallurgica et Materialia 27 (1992) 1533-1538. 